\title{
Photosynthesis Research \\ Whole-tissue determination of the rate coefficients of photoinactivation and repair of Photosystem II in cotton leaf discs based on flash-induced P700 redox kinetics --Manuscript Draft--
}

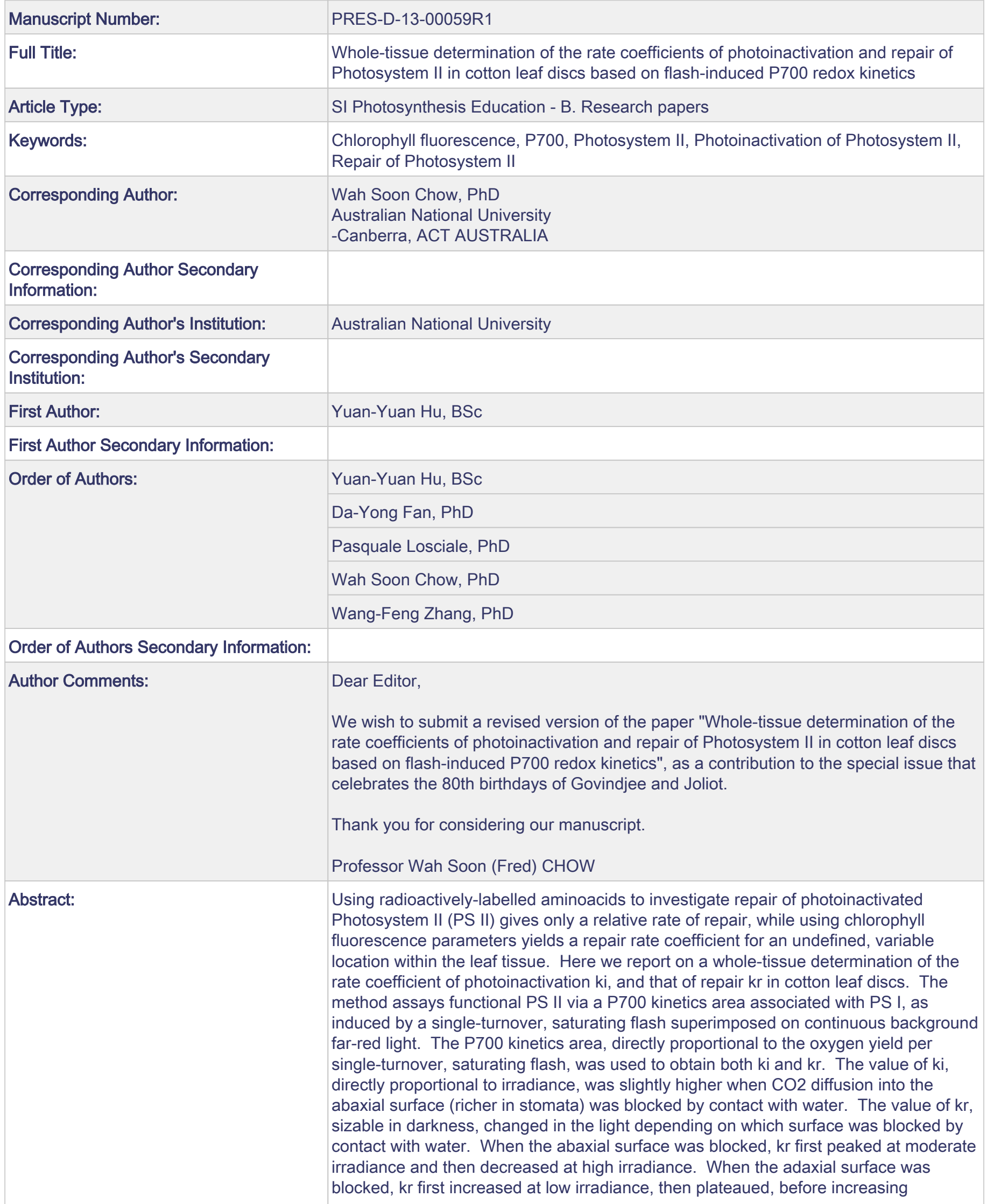


markedly at high irradiance. At the highest irradiance, kr differed by an order of magnitude between the two orientations, attributable to different extents of oxidative stress affecting repair (Nishiyama et al. 2001, EMBO J 20: 5587-5594). The method is a whole-tissue, convenient determination of the rate coefficient of photoinactivation $\mathrm{ki}$ and that of repair kr.

Response to Reviewers:
Dear Editor,

We thank the reviewers for their constructive comments, in response to which we have made the following modifications where needed. Changes in the re-submitted manuscript text are indicated in red.

Reviewer \#1:

It is a very well-written paper and I enjoy reading it. Below are some minor suggestions for the amendments before publication:

P6, line 122, it would be better to include the maximal light intensity under natural light inside the greenhouse from April to August 2012.

RESPONSE: added as suggested

P6, lines 172 to 173, Mexp and Mfitted should be indicated on Fig. 1B or in the Figure Legend of Fig. 1B.

RESPONSE: added in the figure legend as suggested

P10, lines 218 - 224, "Measurement of carbon assimilation rates": "Temperature and chamber $\mathrm{CO} 2$ concentration were kept at $25^{\circ} \mathrm{C}$ and $400 \mu \mathrm{mol}$ mol-1, respectively", what was the source of $\mathrm{CO} 2$, internal supply or ambient [CO2]? When were the measurement carried out during the day?

RESPONSE: added as suggested

P10, lines 225 to 231, "Measurement of electron transport rates". It would be better to include some details on how to obtain PSII. and $Y(I)$

RESPONSE: In the interest of brevity, a full description is not added, but a reference to Khughammer and Schreiber (2007) for details of determining Y(I) and phi PS II has been added

Fig. 4, the symbols of 913 and $1300 \mu \mathrm{mol}$ did not match those shown on the curves. RESPONSE: symbols corrected as suggested

Discussion -This paper also studied and discussed the effect of different $\mathrm{CO} 2$ diffuse (through two orientations in which leaf discs were floated on water) on the rate coefficient of photoinactivation ki and the rate coefficient of repair kr. It is concluded that at the highest irradiance, the repair rate coefficient depends on $\mathrm{CO} 2$ diffusion via stomata, probably reflecting whether oxidative stress exceeded the capacity for detoxifying ROS or not. I am also wondering if cyclic electron flow (CEF) would also affect $\mathrm{ki}$ and $\mathrm{kr}$ as $\mathrm{CO} 2$ diffusion may affect the process of CEF. It has been reported that CEF-dependent generation of $\mathrm{pH}$ across the thylakoid membrane helps to avoid photoinhibition by different photoprotection mechanisms [Takahashi et al. Plant Physiology 149:1560-1567 (2009)]. These are just my comments.

RESPONSE: Thanks for the suggestion. While CEF may well have an effect on ki and $\mathrm{kr}$, the difficulty of quantifying CEF presents a problem. CEF is combined with the linear electron flux and other minor fluxes in the parameter ETR1, the total electron flux through PS I (Fig. 8,), but we are not sure exactly how large the CEF component is. For this reason, we have refrained from bringing the protective effect of CEF into the Discussion.

Reviewer \#2: General comments: This manuscript presents a new method to determine the rate coefficients for photoinactivation and repair of PSII. The flashinduced P700 kinetics that the authors have developed seems to be solid and convenient to monitor the two processes that occur simultaneously in vivo during photoinhibition of PSII. This method allowed the authors to determine the rate coefficients for photoinactivation and repair of PSII in a whole tissue of cotton and also to find that the repair process is susceptible to inactivation under high light when the availability of $\mathrm{CO} 2$ is limited. Based on the findings, they conclude that the repair process is sensitive to oxidative stress. I totally agree with their conclusion. 
Specific comments: 1. In Fig. 6B, profiles of the rate coefficient of repair do not look very consistent. In particular, the rate coefficient in the leaf disc with adaxial side faced water goes up and down. This complicated profile might be due to the results of the repair assay shown in Fig. $5 \mathrm{~B}$. The P700 kinetics area at zero time is not the same in all samples so that the repair rate might be changed (see illumination at 30 and 133). If this is true, I would like to suggest the authors to diminish the discussion about the profile.

RESPONSE: As this reviewer suggested, we have modified the Discussion to simply say that $\mathrm{kr}$ was between 0.55 and $0.75 \mathrm{~h} 1$ in the irradiance range $30-611 \mu \mathrm{mol} \mathrm{m}-2 \mathrm{~s}-1$.

2. In Fig. 6A, there is a slight difference in the rate coefficient of photoinactivation between the two leaves with different orientation. I am a bit wondering if lincomycin can efficiently penetrate into the cells from the adaxial side.

RESPONSE: The slight difference is probably real, and is probably due to a difference in the electron transport rate permitted in the two orientations at a given irradiance, a difference that exists at least above $\sim 300$ umol m-2 s-1. 
Whole-tissue determination of the rate coefficients of photoinactivation and repair of Photosystem

2 II in cotton leaf discs based on flash-induced P700 redox kinetics

Yuan-Yuan $\mathrm{Hu}^{*}$ • Da-Yong Fan ${ }^{*}$ • Pasquale Losciale • Wah Soon Chow • Wang-Feng

4 Zhang

*These authors contributed equally to this work

6

Yuan-Yuan Hu $\quad$ Wang-Feng Zhang $(\bowtie)$

8 The Key Laboratory of Oasis Eco-agriculture, Xinjiang Production and Construction Group, Shihezi University, Shihezi 832003, P.R. China

10 e-mail: zhwf_agr@shzu.edu.cn

Yuan-Yuan Hu Da-Yong Fan Wah Soon Chow $(\bowtie)$

12 Division of Plant Science, Research School of Biology, R.N. Robertson Building (46), The Australian National University, Canberra, ACT 0200, Australia

14 e-mail: Fred.Chow@anu.edu.au

Da-Yong Fan

16 State Key Laboratory of Vegetation and Environmental Change, Institute of Botany, The Chinese Academy of Sciences, 100093 Beijing, China

18 Pasquale Losciale

Consiglio per la Ricerca e la sperimentazione in Agricoltura [Research Unit for Agriculture in Dry

20 Environments], 70125, Bari, Italy.

Pasquale Losciale

22 Dipartimento di Scienze Agrarie, University of Bologna, 40127 Bologna, Italy. 


\section{Abstract}

Using radioactively-labelled aminoacids to investigate repair of photoinactivated Photosystem II (PS II)

26 gives only a relative rate of repair, while using chlorophyll fluorescence parameters yields a repair rate coefficient for an undefined, variable location within the leaf tissue. Here we report on a whole-tissue

28 determination of the rate coefficient of photoinactivation $k_{i}$, and that of repair $k_{r}$ in cotton leaf discs. The method assays functional PS II via a P700 kinetics area associated with PS I, as induced by a

30 single-turnover, saturating flash superimposed on continuous background far-red light. The P700 kinetics area, directly proportional to the oxygen yield per single-turnover, saturating flash, was used to

32 obtain both $k_{i}$ and $k_{r}$. The value of $k_{i}$, directly proportional to irradiance, was slightly higher when $\mathrm{CO}_{2}$ diffusion into the abaxial surface (richer in stomata) was blocked by contact with water. The value of $k_{r}$, sizable in darkness, changed in the light depending on which surface was blocked by contact with water. When the abaxial surface was blocked, $k_{r}$ first peaked at moderate irradiance and then decreased at high irradiance. When the adaxial surface was blocked, $k_{r}$ first increased at low irradiance, then plateaued, before increasing markedly at high irradiance. At the highest irradiance, $k_{r}$ differed by an order of magnitude between the two orientations, attributable to different extents of oxidative stress affecting repair (Nishiyama et al. 2001, EMBO J 20: 5587-5594). The method is a whole-tissue, convenient

40 determination of the rate coefficient of photoinactivation $k_{i}$ and that of repair $k_{r}$.

Photosystem II • Repair of Photosystem II

\begin{tabular}{lll}
\multicolumn{3}{c}{ Abbreviations } \\
46 & Chl & chlorophyll \\
& $f$ & functional fraction of PS II
\end{tabular}


$=\left(F_{m}-F_{o}\right)$, variable fluorescence

$50 \quad k_{i}, k_{r}$

rate coefficient of photoinactivation and repair, respectively

P700

special Chl pair in the PSI reaction center

$52 \quad$ PI

photoinactivation

PS

photosystem

$54 \quad \mathrm{ROS}$

reactive oxygen species

Introduction

While light is essential for photosynthesis, too much light can lead to dysfunction of the photosynthetic apparatus (Ewart 1896; Powles 1984; Tyystjärvi 2008; Nishiyama et al. 2011; Oguchi et al. 2011a; Ohad et al. 2011; Vass 2011) because oxygenic photosynthesis, i.e. Photosystem II (PS II), is intrinsically suicidal (van Gorkom and Schelvis 1993). After photoinactivation, PS II needs to be repaired (Prásil et al. 1992; Aro et al. 1993; Melis 1999; Chow and Aro 2005). During illumination, both photoinactivation and repair occur simultaneously. If repair cannot keep up with photoinactivation, net loss of PS II function ensues. When repair keeps up with photoinactivation, the whole PS II

64 population may turn over at least once during a sunny day. The underlying mechanism of repair and the associated energy cost (Raven 2011; Miyata et al. 2012) are crucial for understanding how leaves

66 alleviate light-induced decrease of photochemical efficiency of PSII on the one hand and balance their energy budget on the other, including leaves of woody plants grown in the field (Losciale et al. 2010).

Repair of photoinactivated PS II requires de novo synthesis of the D1 protein in the PS II reaction centre, as shown, for example, in Chlamydomonas (Kyle et al. 1984; Ohad et al. 1984), Anacystis (Samuelsson et al. 1985), pea (Ohad et al. 1985) and beans (Greer et al. 1986). Protein synthesis can be 
monitored by the incorporation of radioactively-labelled aminoacids into proteins (Fish and Jagendorf 1982; Mattoo et al. 1984; Aro et al. 1992). For example, Sundby et al. (1993) studied the parallel synthesis and degradation of the D1 protein in Brassica napus leaves by measuring (1) the net

74 incorporation of ${ }^{35} \mathrm{~S}$-methionine as a function of irradiance at a fixed duration of illumination (1 h) and (2) D1 protein degradation as revealed by the exponential loss of radiolabel in a pulse-chase experiment.

76 Chow (2001) used the data of Sundby et al. (1993) to derive the gross rate of D1 protein synthesis (in arbitrary units) as a function of irradiance. However, the use of radiolabel is not always convenient, and 78 the results give only relative rates of photoinactivation and repair.

Photoinactivation and repair of PS II are best characterized by their rate coefficients. The rate 80 coefficient of photoinactivation $k_{i}$ can be obtained from the first-order time course of the loss of functional PS II in the absence of repair (e.g. in the presence of lincomycin, Tyystjärvi and Aro 1996; Kou et al. 2012); once obtained, it can be multiplied by the concentration of functional PS II to give the rate of photoinactivation. The rate coefficient of repair $k_{r}$ can deduced from the parallel photoinactivation (with

$84 k_{i}$ separately determined in the absence of repair under otherwise identical conditions) and recovery processes that occur in the presence of repair; once obtained, it can be multiplied by the concentration of non-functional PS II to give the rate of recovery. The in vivo PSII functionality could be assessed by using chlorophyll $a$ fluorescence or oxygen evolution. However, these two methods have their drawbacks (Chow et al. 2012). For example, one inherent problem of using Chl fluorescence is that the signal is detected from an unspecified depth in the leaf tissue, and that the depth of signal detection may well vary during the course of the experiment: as functional PS II complexes are rendered less fluorescent upon photoinactivation, the contribution to the Chl fluorescence yield from deeper tissue becomes more prominent (Oguchi et al. 2011b). That is, a moving target that represents a sub-population of PS II is monitored during the onset of PS II photoinactivation as well as recovery from photoinactivation. This 
inherent problem of using Chl fluorescence is that the use of $F_{v} / F_{m}$ or $1 / F_{o}-1 / F_{m}$ (to represent PS II functionality) could be reliably obtained only after darkness of a certain duration, mainly to allow relaxation of energy-dependent quenching. However, if the repair process persists in darkness (see results below), a long dark treatment before measurement will inevitably complicate the actual repair that has occurred in the light. convenient, and can be applied as soon as $1 \mathrm{~min}$ after the cessation of a light treatment, provided the flash 102 is saturating. The integrated delivery of electrons from PS II to $\mathrm{P} 700^{+}$(the oxidized primary donor in PS I), after a single-turnover saturating flash, is a whole-tissue measure of the functional PS II content, as 104 supported by two findings. First, a simple analysis of the integrated flash-induced delivery of electrons to $\mathrm{P} 70^{+}$gave a single linear correlation with the relative oxygen yield per repetitive flash for various plant species of diverse anatomy (Losciale et al. 2008; for a review of assays of PS II in vivo, see Chow et al. 2012). Second, a simple flash-induced P700 redox kinetics area was measured, bounded by (1) the horizontal line corresponding to the steady-state value in background far-red light and (2) the re-reduction of $\mathrm{P} 700^{+}$and the oxidation of P700 following a saturating, single-turnover flash; this P700 kinetics area, 110 measured from either the upper (adaxial) side or the lower (abaxial) side of a leaf, gave essentially the same fraction of functional PS II remaining after photoinhibition (Oguchi et al. 2011b). We took 112 advantage of this simple flash-induced P700 redox kinetics area to assay the relative content of functional PS II in the whole tissue, and to evaluate the rate coefficients of photoinactivation and repair of PS II in 114 cotton leaves under varied irradiance and oxidative stress. The results demonstrate a reliable method for characterizing both photoinactivation of PS II and recovery from photoinactivation in the whole leaf tissue, superior to the use of Chl fluorescence. Further, we observed that the rate coefficient of repair can be highly sensitive to oxidative stress. 


\section{Materials and methods}

\section{Growth of plants}

Cotton (Gossypium hirsutum L. cv. Deltapine) plants were grown in a glasshouse at approximately $28 / 18^{\circ} \mathrm{C}$ (day/night) under natural light (maximum irradiance $\sim 1000 \mu \mathrm{mol} \mathrm{m}^{-2} \mathrm{~s}^{-1}$ ) from April to August 2012. The plants were provided with a nutrient solution of “Aquasol” (Yates Australia, Padstow, NSW).

\section{Photoinhibitory treatment of leaf discs}

For photoinactivation of PS II in the presence of lincomycin, cotton leaf discs $\left(1.5 \mathrm{~cm}^{2}\right)$ were first floated

126 on $1 \mathrm{mM}$ lincomycin solution overnight in darkness to allow uptake of the inhibitor of chloroplast-encoded protein synthesis. Leaf discs that were to be exposed to photoinhibitory light with

128 the abaxial side facing air were floated overnight in darkness with the adaxial side in contact with a lincomycin solution in a clear petri dish; the subsequent light exposure was applied vertically up onto the

130 adaxial side. Leaf discs that were to be exposed to photoinhibitory light with the adaxial side facing air were floated overnight in darkness with the abaxial side in contact with a lincomycin solution; the subsequent light exposure was applied vertically down onto the adaxial side. Illumination was applied for up to $6 \mathrm{~h}$ to obtain the first-order time course of photoinactivation of PS II, which yielded the rate coefficient of photoinactivation $k_{i}$.

For observing the time course of recovery of PS II after photoinactivation, leaf discs were

136 immersed under water $\left(\sim 15^{\circ} \mathrm{C}\right)$ in the absence of lincomycin, and pre-illuminated on the adaxial side with light $\left(1800 \mu \mathrm{mol}\right.$ photons $\left.\mathrm{m}^{-2} \mathrm{~s}^{-1}\right)$ from an HMI Universal Spotlight (Model HMI 575 W/GS; Osram)

138 behind a heat-reflecting filter (Schott 115, Tempax) and a piece of soda glass. The duration of pre-illumination needed to decrease the functional PS II content to $\sim 50 \%$ was found to be 72 min, after

140 which leaf discs were allowed to recover under varied irradiance applied to the adaxial side, with either the abaxial or adaxial side facing air, while the opposite side was in contact with water. Depending on 
142 the selected orientation, illumination was provided vertically up or down, always to the adaxial side. The pre-treatment at a lower temperature and high irradiance speeded up photoinactivation of PS II, while

144 the relatively low $\left[\mathrm{O}_{2}\right]$ in the vicinity of the submerged leaf discs during high-light treatment allowed good recovery to be measured, at least at low irradiances.

\section{PSII functionality}

A time-consuming method of quantifying the functional PSII content is based on the flash-induced

148 oxygen evolution in $1 \% \mathrm{CO}_{2}$, using repetitive single-turnover, saturating xenon flashes (full width at half height $=3 \mu \mathrm{s}$ ) and assuming that each functional PSII evolves one $\mathrm{O}_{2}$ molecule after four flashes (Chow

150 et al. 1989). The $\mathrm{O}_{2}$ yield flash ${ }^{-1} \mathrm{~m}^{-2}$ of photoinhibited leaf segments was normalized to the value of the non-photoinhibited control to obtain the functional fraction of PSII remaining. The functional fraction

152 of PS II so obtained was used to check a simple flash-induced P700 redox kinetics area which was determined immediately after the $\mathrm{O}_{2}$ measurement, as described below.

\section{Measurement of redox kinetics of P700}

Leaf segments were used for measurement of redox changes of P700 with a dual wavelength $(810 / 870$ nm) unit (ED-P700DW) attached to a phase amplitude modulation fluorometer (PAM 101/102/103, Walz, Effeltrich, Germany) and used in the reflectance mode (Chow and Hope 2004). To obtain redox changes

158 due to a flash superimposed on continuous far-red light, a steady-state was sought by illumination with far-red light (12 $\mu \mathrm{mol}$ photons $\mathrm{m}^{-2} \mathrm{~s}^{-1}$, peak wavelength $729 \mathrm{~nm}, 102-\mathrm{FR}$, Walz, Effeltrich, Germany) for

$160 \geq 1 \mathrm{~min}$. Then a single-turnover, saturating xenon flash (Walz XST 103 xenon flash, full width at half height $=9 \mu \mathrm{s})$ was applied to the adaxial side of the leaf disc. When necessary, the transmitted energy of

162 the flashes was lowered in steps by introducing neutral density films (Lee filters, Mediavision, Australia). Timing of the start of data acquisition (time constant $=95 \mu \mathrm{s}$ ), the triggering of the flash, and the repetition rate were controlled by a pulse/delay generator (Model 555, Berkeley Nucleonics Corporation, 
USA). The analogue output from the fluorometer was digitized and stored in a computer using a program written by the late A.B. Hope. Flashes were given at $0.2 \mathrm{~Hz}$, and 4 consecutive signals were averaged automatically. The maximum signal immediately after the flash was taken as the total amount 168 of photo-oxidizable P700, and used to normalize the trace (Fig. 1A). The area bounded by the trace and the horizontal line corresponding to steady state in continuous weak far-red light is here termed the P700

170 kinetics area (the shaded area in Fig. 1A).

Lowering the flash intensity by neutral density films produced a smaller P700 kinetics area.

172 At the maximum flash energy, the measured relative maximum area $\left(\mathrm{M}_{\mathrm{exp}}\right)$ was found to be almost identical to the extrapolated maximum area obtained by curve fitting ( $\left.\mathrm{M}_{\text {fitted }}\right)$ : $\mathrm{M}_{\mathrm{exp}}$ and $\mathrm{M}_{\text {fitted }}$ values were

17494.5 and 94.1 for control leaf discs; 55.6 and 54.8 for leaf discs photoinhibited in the absence of lincomycin; and 45.7 and 45.4 for leaf discs photoinhibited in the presence of lincomycin, respectively

176 (Fig. 1B).

The P700 kinetics area of a sample after photoinhibition pretreatment was obtained 178 approximately $1 \mathrm{~min}$ after the end of high-light pre-treatment. To test the extent to which the P700 kinetics area, obtained with a saturating/near-saturating flash, is affected by energy-dependent quenching, 180 we measured the P700 kinetics area (obtained using the maximum flash energy) as a function of dark time after cessation of actinic illumination. Control leaf discs were pre-illuminated with white LED actinic 182 light at $1500 \mu \mathrm{mol}$ photons $\mathrm{m}^{-2} \mathrm{~s}^{-1}$ for $5 \mathrm{~min}$, so as to induce steady-state photosynthesis, with weak background far-red light present throughout. Photoinhibted leaf discs were taken from the 184 photoinhibition light (30 $\mathrm{min}$ at $1700 \mu \mathrm{mol}$ photons $\mathrm{m}^{-2} \mathrm{~s}^{-1}$ ) and immediately exposed to white LED actinic light at $1500 \mu \mathrm{mol}$ photons $\mathrm{m}^{-2} \mathrm{~s}^{-1}$ for only $1 \mathrm{~min}$ to maintain steady-state photosynthesis while minimizing further photoinactivation of PS II, weak background far-red light being present. To begin measurements, promptly after the 5-min/1-min pre-illumination, a pulse/delay generator started a new 
that the actinic illumination ceased (at time $t=0)$, a 1-s pulse of strong far-red light $(\sim 2000 \mu$ mol photons $\mathrm{m}^{-2} \mathrm{~s}^{-1}$, applied to the abaxial side from below) helped to quickly bring the concentration of $\mathrm{P} 700^{+}$ towards the steady state level corresponding to the weak far-red light alone. At a selected time $t(\geq 3 \mathrm{~s})$

192 after cessation of actinic illumination in near darkness (the weak far-red light being on), data acquisition was started by the pulse-delay generator; then at time $(t+0.05) \mathrm{s}$, the xenon flash was triggered, and the

194 P700 kinetics curve recorded to yield the P700 kinetics area. In this way, the 'dark' time $t$ was varied from $3 \mathrm{~s}$ to $60 \mathrm{~s}$, during which energy-dependent quenching was expected to relax gradually. Fig. 1C 196 shows that at $t=60 \mathrm{~s}$, the kinetics area was within $\sim 2 \%$ of the maximum that was obtained in the presence of weak far-red light and before any actinic illumination, whether a sample was a control 198 (squares) or one that had been photoinhibited in the presence of lincomycin (triangles).

Determination of rate coefficients of photoinactivation and repair using a simple P700 kinetics area as a measure of the functional PS II population in the whole tissue

The maximum P700 kinetic area of a control sample at flash saturation is taken to represent the fraction $f$ $=1$ of functional PS II. The exponential decrease (Kou et al. 2012) of $f$ from the value 1 during the onset of photoinactivation of PS II in the absence of repair (i.e., in the presence of lincomycin) gives the rate coefficient of photoinactivation $k_{i}$ at a given irradiance. That is, at any time $t$ the rate of photoinactivation PS II is

$$
d f / d t=-k_{i} f
$$

During recovery from photoinactivation at a given irradiance, both photoinactivation and repair

208 occur simultaneously. The rate of repair is directly proportional to the fraction of non-functional PS II,

$(1-f)$. During recovery at a given irradiance, the net rate of increase in $f$ is the algebraic sum of the two rates:

$$
d f / d t=k_{r}(1-f)-k_{i} f
$$

212 When recovery occurs from time $t=0$ at $f=f_{0}$ (typically $\sim 0.5$ ), the solution of the above equation is (He 
and Chow 2003):

$$
f(t)=\left(f_{0}-\frac{k_{r}}{k_{i}+k_{r}}\right) e^{-\left(k_{i}+k_{r}\right) t}+\frac{k_{r}}{k_{i}+k_{r}}
$$

This equation was used to fit the recovery data points using the software Origin 7 (Microcal Software Inc,

216 Northhampton, MA, USA), allowing $k_{i}$ and $k_{r}$ to vary from initial estimates until stable values are obtained after a number of iterations.

\section{Measurement of carbon assimilation rates}

Gas-exchange measurements were determined in the afternoon with main-stem leaves using a portable open-circuit infra-red gas analyzer (LI6400, LI-COR, Lincoln, USA), and a normal $2 \mathrm{~cm} \times 3 \mathrm{~cm}$ chamber with a 6400-02B (LI-COR) light emitting diode light source was used. Leaves attached to cotton plants were first kept at $2000 \mu \mathrm{mol} \mathrm{m} \mathrm{m}^{-2}$ for at least $30 \mathrm{~min}$; thereafter, the irradiance was decreased in a stepwise manner. Leaf temperature and chamber $\mathrm{CO}_{2}$ concentration were kept at $25^{\circ} \mathrm{C}$ and $400 \mu \mathrm{mol}$ $\mathrm{mol}^{-1}$ (supplied from a $\mathrm{CO}_{2}$ cartridge), respectively.

\section{Measurement of electron transport rates}

226 The total electron transport rate through PS I (ETR1) was obtained as the product $\mathrm{Y}(\mathrm{I}) \times$ irradiance $\times 0.85$ $\times 0.5$, where $\mathrm{Y}(\mathrm{I})$ is the photochemical yield of PS I. The rate of linear electron flow through PS II was determined as the product $\phi_{P S ~ I I} \times$ irradiance $\times 0.85 \times 0.5 \quad$ Both $\mathrm{Y}(\mathrm{I})$ and $\phi_{P S ~ I I}$ were determined using a Dual-PAM (Walz, Effeltrich, Germany), as described by Miyake et al. (2005) and Klughammer and Schreiber (2007), assuming that the leaf absorptance was 0.85 and equal partitioning of absorbed light energy between the two photosystems.

\section{Results}

\section{Linear correlation of P700 kinetics area with the $\mathbf{O}_{2}$ yield per single-turnover flash}


PSII functionality was monitored in leaf discs after photoinactivation in the presence of lincomycin, an inhibitor of repair that depends on chloroplast-encoded protein synthesis. The number of functional PSII complexes in leaf segments was quantified by the oxygen yield per flash, followed by measurement

238 of the flash-induced P700 kinetics area. Fig. 2 shows the correlation between P700 kinetics area and the oxygen yield per flash for cotton. The data points are scattered on both sides of a straight line through

240 the origin $(0,0)$ and the point $(100,100)$, showing a one-to-one empirical relationship between the two parameters. That there is a one-to-one correlation is not surprising: both parameters are whole-tissue

242 values, one measuring the release of electrons from the splitting of water molecules in PS II, and the other measuring the cumulative delivery of electrons from PS II to P700.

\section{Recovery of PS II in cotton in darkness from photoinactivation is largely inhibited by lincomycin}

Given that the P700 kinetics area is a rapid measurement, it offers the possibility of monitoring the functionality of PS II at various times after a photoinactivation treatment. In the absence of lincomycin, the P700 kinetics area in darkness increased gradually from the cessation of photoinactivation light treatment (Fig. 3, open circles). When cotton leaf discs were pre-infiltrated with lincomycin before photoinactivation light treatment, on the other hand, there was only a little increase in P700 kinetics area in darkness after the light treatment (Fig. 3, closed squares). When infiltration with lincomycin was done after the photoinactivation light treatment, substantial recovery occurred initially while the inhibitor was not yet fully effective (Fig. 3, closed circles). For all subsequently measurements of the P700 kinetics area, in a compromise between minimizing repair in the dark and minimizing energy-dependent quenching, we chose to make the measurements at $t \approx 1 \mathrm{~min}$ after a photoinactivation treatment.

\section{Photoinactivation of PS II and recovery in the light while the adaxial side of leaf discs faced air}

256 We investigated the time course of photoinactivation of PS II in the absence of repair by floating leaf discs with the abaxial side (richer in stomates) in contact with a lincomycin solution and the adaxial side 
facing air, while illuminating the adaxial side at an irradiance of $1300 \mu \mathrm{mol} \mathrm{m} \mathrm{m}^{-2} \mathrm{~s}^{-1}$. This is an orientation that substantially restricts the diffusion of $\mathrm{CO}_{2}$ into the leaf tissue. Fig. $4 \mathrm{~A}$ depicts the negative exponential time courses in the presence of lincomycin. That is, the functional PS II content decreased with first-order kinetics (Tyystjärvi and Aro 1996; Kou et al. 2012).

Fig. 4B shows the recovery of PS II from a photoinactivation pre-treatment (in the absence of lincomycin) which had decreased $f$ to approximately 0.5 . The recovery took place at $25^{\circ} \mathrm{C}$ and at 264 various irradiances, including darkness, with the adaxial side of leaf discs facing air and the abaxial side in contact with water. During recovery in the absence of lincomycin, both photoinactivation and repair occur simultaneously, and the time course of changes in the P700 kinetics area represents the net sum of photoinactivation and repair. In darkness, there was clear recovery (closed squares, Fig. 4B). Net recovery was near optimal at low irradiance, e.g. $27 \mu \mathrm{mol} \mathrm{m} \mathrm{m}^{-2}$. At high irradiance, however, net loss of P700 kinetics area (functional PS II) was observed during the 'recovery' phase. By fitting curves to the data points according to equation (3) using the $k_{i}$ values from Fig. 4A, we obtained the fitted curves plotted in Fig. 4B as well as the $k_{r}$ values (see below).

\section{Photoinactivation of PS II and recovery in the light while the abaxial side of leaf discs faced air}

We next investigated the time course of photoinactivation of PS II in the absence of repair by floating leaf

274 discs on a lincomycin solution with the abaxial side facing air, while illuminating the adaxial side at an irradiance of $1300 \mu \mathrm{mol} \mathrm{m}{ }^{-2} \mathrm{~s}^{-1}$, with the light directed upwards at the adaxial side. This orientation 276 allowed easier diffusion of $\mathrm{CO}_{2}$ into the leaf tissue. Fig. 5A depicts the negative exponential time courses of photoinactivation in the presence of lincomycin. That is, the functional PS II content in leaf 278 discs in this orientation also decreased with first-order kinetics, as observed in the previous orientation.

Fig. 5B shows the recovery of PS II from a photoinactivation pre-treatment (in the absence of lincomycin) which had decreased $f$ to approximately 0.5 . The recovery took place at $25^{\circ} \mathrm{C}$ and at various irradiances, including darkness, with the abaxial side of leaf discs facing air and the adaxial side 

recovery was near optimal at low irradiance, e.g. $30 \mu \mathrm{mol} \mathrm{m} \mathrm{m}^{-1}$. At high irradiance, recovery occurred according to equation (3) using the $k_{i}$ values from Fig. 5A, we obtained the fitted curves plotted in Fig. 5B as well as the $k_{r}$ values (see below).

\section{Variation of $k_{i}$ and $k_{r}$ with irradiance}

288 The rate coefficient of photoinactivation $k_{i}$ increased linearly with irradiance. At a given irradiance, $k_{i}$ was marginally smaller when the adaxial side of leaf discs was in contact with a lincomycin solution, while the abaxial side faced air (Fig. 6A), thereby allowing easier diffusion of $\mathrm{CO}_{2}$ into leaf tissue.

The variation of $k_{r}$ with irradiance was more complex. In darkness, $k_{r}$ was about $0.16 \mathrm{~h}^{-1}$ (non-zero) in both orientations of leaf discs (Fig. 6B). When the abaxial side faced air and the adaxial side faced water, $k_{r}$ increased rapidly at low irradiance; it then remained on a plateau until the irradiance exceeded $600 \mu \mathrm{mol} \mathrm{m} \mathrm{s}^{-1}$. Above $600 \mu \mathrm{mol} \mathrm{m} \mathrm{m}^{-2}$, it again increased substantially, reaching $1.6 \mathrm{~h}^{-1}$. When the adaxial side faced air and the abaxial side was in contact with water, $k_{r}$ increased to a peak at about $350 \mu \mathrm{mol} \mathrm{m} \mathrm{s}^{-1}$ but declined at higher irradiances (Fig. 6B). At the highest irradiance, $k_{r}$ differed by an order of magnitude between the two orientations.

\section{Response of rates of carbon assimilation and electron transport to irradiance}

The net rate of carbon assimilation of cotton leaves was determined as function of irradiance (Fig. 7).

300 The most rapid increase in the observed carbon assimilation rate occurred over the irradiance interval 0-600 $\mu \mathrm{mol} \mathrm{m}^{-2} \mathrm{~s}^{-1}$. The total rate of electron transport through PS I (ETR1) assayed by the P700 signal, 302 and the rate of linear electron transport through PS II (ETR2) assayed by Chl fluorescence are depicted in Fig. 8. From moderate to high light, each rate was higher when the abaxial side faced air, allowing better diffusion of $\mathrm{CO}_{2}$ into the leaf tissue. 


\section{Discussion}

\section{The P700 kinetics area represents electrons delivered from PS II to $\mathrm{P700}^{+}$in the whole leaf tissue}

308 The P700 kinetics area, indicated as a shaded area in Fig. 1A, decreased during progressive photoinactivation pre-treatment of PS II. Using the Walz single-turnover flash at maximum intensity, we obtained an area that was practically identical to the extrapolated maximum obtained by curve fitting (Fig. $1 \mathrm{~B})$; that is, the flash was saturating for leaf discs which were in a 'relaxed' state in the presence of weak

312 far-red light alone. This maximum corresponded to the capacity for flash-induced delivery of electrons from the functional PS II complexes to P700+.

However, the possibility of increased energy-dependent quenching persisting after high-light treatment of leaf discs, reducing delivery of excitation to the PS II reaction centre, and making the flash

316 less than saturating, could not be excluded. Indeed, lincomycin treatment of leaves under high light has the potential to lower the quantum efficiency of PS II by slowing the relaxation of non-photochemical quenching (Bachmann et al. 2004). Nevertheless, as our measurements were made approximately $1 \mathrm{~min}$ after cessation of light treatment for photoinactivation or recovery, it appears that energy-dependent quenching seemed to have diminished sufficiently for the Walz flash to be saturating (Fig. 1C). The results mean that this technique is usable at 1 min or longer after cessation of a light treatment; to employ

322 a shorter dark time would require a stronger flash to ensure saturation in the presence of strong energy-dependent quenching.

The P700 kinetics area was directly proportional to the oxygen yield per single-turnover flash in repetitive-flash illumination of cotton leaf discs (Fig. 2). Spinach and capsicum also followed a single one-to-one relation (Kou et al. 2012). This simple, empirical correlation forms the basis on which a rapid relative assay of functional PS II content is conducted. 
Both are whole-tissue measurements: the measuring beam at $810 \mathrm{~nm}$ that reports the $\mathrm{P} 700^{+}$signal is multiply scattered in the leaf tissue until it is eventually absorbed by $\mathrm{P} 00^{+}$, while oxygen is evolved from throughout the tissue on excitation of PS II with single-turnover, saturating flashes. Indeed, the P700

332 kinetics area of a photoinactivated sample relative to that of a control is similar, whether measured from the adaxial or the abaxial side of photoinhibited leaves (Fig. 3 in Oguchi et al. 2011b). This superior

334 feature of the $\mathrm{P} 700^{+}$signal contrasts with the variably localized detection of the Chl fluorescence signal (Terashima et al. 2009). Further, the depth of Chl fluorescence signal detection may well vary during 336 the time courses of photoinactivation of PS II and recovery as the contribution to the fluorescence intensity from a particular depth varies. photo-oxidizable P700 signal did not decline after high-light treatment. Under most circumstances at favourable temperatures, this is the case, as PS I is normally well protected against photoinhibitory damage at normal temperatures. Indeed, photoinactivation of PS II in cotton leaf discs in either the

342 presence or absence of lincomycin in the present study did not significantly decrease the maximum photo-oxidizable P700 signal induced by a flash superimposed on background far-red light (data not

344 shown), indicating no photodamage to PS I. Another assumption is that the two photosystems operate in series, such that all electrons originating from water splitting in PS II arrive at $\mathrm{P} 700^{+}$. This measurement may be reasonable in leaf tissue under weak far-red light to which a flash is added.

\section{Recovery of PS II in darkness}

348 In this whole-tissue assay of functional PS II in cotton, slow but steady recovery of PS II from photoinactivation was observed in darkness (Figs. 3, 4B and 5B). Perhaps after illumination with strong light, mitochondria supplied the ATP needed for biochemical reactions required to replace photodamaged D1 protein by newly synthesized D1 protein (Mattoo et al. 1984; Taniguchi et al. 1993) or for the uptake 
of cytoplasmically synthesized polypeptides into the chloroplast (Grossman et al. 1980). Indeed, recovery could be partially induced by floating photoinhibited leaf segments on a $50 \mathrm{mM}$ solution of ATP in the dark (H.-Y. Lee and W.S. Chow, unpublished).

In any case, recovery of PS II in cotton leaf discs in the dark was largely inhibited by 356 lincomycin, provided sufficient time was allowed for the uptake of lincomycin into the chloroplast (Fig. 3), demonstrating that by far the major part of the recovery was sensitive to an inhibitor of 358 chloroplast-encoded protein synthesis. A small residual recovery in darkness could be seen in cotton in the presence of lincomycin, amounting to about $3 \%$ of the total population of PS II, functional or

360 non-functional. In spinach, bean and maize, the lincomycin-insensitive recovery in $5 \mathrm{~h}$ darkness was larger than in cotton, being $12 \%, 20 \%$ and $25 \%$ of the total PS II population, respectively (data not shown). This residual recovery could represent (1) the reversible inactivation of PS II that is unrelated to D1 protein synthesis (Hong and Xu 1999), (2) a readily-available pool of D1 protein not yet

364 incorporated into PS II in thylakoids (Wettern 1986) and/or (3) the inability of lincomycin to reach all D1 synthesis sites. This lincomycin-insensitive recovery component was reported for low light conditions,

366 using dark-relaxed $F_{v} / F_{m}$ to assay photodamage (Aro et al. 1993). Our measurement of the P700 kinetics area was made at approximately $1 \mathrm{~min}$ after the cessation of recovery-light treatment, not long enough to allow any substantial recovery in darkness, but long enough to allow energy-dependent quenching to relax to such an extent that the flash was saturating.

\section{The rate coefficient of photoinactivation $\boldsymbol{k}_{i}$}

The rate coefficient of photoinactivation $k_{i}$ was directly proportional to irradiance, as previously reported

372 (Tyystjärvi and Aro 1996; Lee et al. 2001; Kato et al. 2003). Its value at a given irradiance was slightly different between the two orientations of floating leaf discs on a lincomycin solution during illumination on the adaxial side (Fig. 6A). Leaf discs floated with their abaxial side facing air had a smaller $k_{i}$, consistent with better $\mathrm{CO}_{2}$ diffusion into leaf tissue and less excess light energy leading to one of the dual 
mechanisms of photoinactivation (Oguchi et al. 2009, 2011a, 2011b); indeed, leaf discs floated in this orientation exhibited a (24-33\%) higher rate of electron transport at saturating irradiance, assayed either as linear electron flow through PS II via Chl fluorescence or as the total electron flux through PS I via P700 redox measurement (Fig. 8).

\section{The rate coefficient of repair $k_{r}$}

By far, the greatest difference between the two orientations resided in the rate coefficient of recovery $k_{r}$

382 (Fig. 6B). In leaf discs floated with their abaxial side facing water, $k_{r}$ increased from $0.16 \mathrm{~h}^{-1}$ in darkness to a peak of about $0.55 \mathrm{~h}^{-1}$ at an irradiance of about $350 \mu \mathrm{mol} \mathrm{m}{ }^{-2} \mathrm{~s}^{-1}$; thereafter, it declined at

384 high irradiance, reaching at the highest irradiance a value similar to that in darkness. This rise-and-fall behaviour of cotton is qualitatively similar to that observed in Capsicum annuит using Chl fluorescence when leaf discs were also floated with their abaxial side in contact with water while the adaxial side faced air (He and Chow 2003). He and Chow (2003) invoked the suggestion of Nishiyama et al. $(2001,2011)$ to explain the surprisingly low $k_{r}$ at high irradiance, just when repair of is most needed: the restriction of $\mathrm{CO}_{2}$ entry into leaf tissue may lead to $\mathrm{O}_{2}$ playing a more prominent role as an electron acceptor, with the consequent enhancement of oxidative stress which impaired repair (Nishiyama et al. 2001, 2011).

When leaf discs were floated with their abaxial side facing air, $k_{r}$ was between 0.55 and 0.75

$392 \mathrm{~h}^{-1}$ in the irradiance range $30-611 \mu \mathrm{mol} \mathrm{m}{ }^{-2} \mathrm{~s}^{-1}$. It was only at much higher irradiance that $k_{r}$ increased again (Fig. 6B). The highest $k_{r}$ observed at the highest irradiance was $1.6 \mathrm{~h}^{-1}$. Considering gross

394 recovery only, without taking into account the concomitant photoinactivation (i.e., setting $k_{i}=0$ ), equation (3) becomes:

$$
f(t)=\left(f_{0}-1\right) e^{-k_{r} t}+1
$$

At time $t_{1 / 2}$, when half of the non-functional PS II complexes have recovered function,

$$
\frac{1-f\left(t_{1 / 2}\right)}{1-f_{0}}=e^{-k_{r} t_{1 / 2}}=0.5
$$


For $k_{r}=1.6 \mathrm{~h}^{-1}$, we obtain $t_{1 / 2}=26 \mathrm{~min}$. That is, half of the non-functional PS II complexes would have recovered function in $26 \mathrm{~min}$ if concurrent photoinactivation had not occurred. In the other orientation of leaf discs, however, $k_{r}$ was an order of magnitude smaller at the highest irradiance, and the $t_{1 / 2}$ correspondingly longer.

It is not clear why $k_{r}$, while remaining at moderately high, did not increase over the irradiance

404 interval 30-600 $\mu \mathrm{mol} \mathrm{m} \mathrm{m}^{-1}$ when leaf discs were floated with their adaxial side in contact with water. One possible reason is that much of the increase in carbon assimilation rate in a leaf attached to the plant 406 occurred over this irradiance range (Fig. 7). Further, under conditions of recovery, the electron transport rate was saturated at about $600 \mu \mathrm{mol} \mathrm{m} \mathrm{s}^{-1}$ or lower, depending on the orientation of leaf discs floating on water (Fig. 8). Perhaps until light saturation, carbon assimilation out-competed repair of PS II for the available ATP.

A relatively small difference was observed between the two orientations of leaf discs in terms of the rate of electron transport, assayed as either the total electron flux through PS I (ETR1, 24\%) at the 412 highest irradiance or as linear electron flow through PS II via Chl fluorescence (ETR2, 27\%) (Fig. 8). It is consistent with a slightly $(27 \%)$ lower stomatal density on the adaxial side compared with the abaxial

414 side (determined for another cultivar grown in the field by $\mathrm{Hu}$ et al. 2013). For such a small difference in stomatal density, it is surprising that the difference in $k_{r}$ between the two orientations was an order of 416 magnitude (Fig. 6B). A possible explanation is that when the abaxial side faced air, $\mathrm{CO}_{2}$ diffusion into the leaf tissue was able to meet photosynthetic demand, and the production of reactive oxygen species (ROS) was still below the capacity of the scavenging enzymes to detoxify the ROS. On the other hand, when the abaxial side was in contact with water, oxidative stress could have exceeded the capacity of the 
Using the P700 kinetics area as a convenient and whole-tissue measure of functional PS II, we

424 obtained the rate coefficients of photoinactivation and repair of PS II for cotton leaf segments. In darkness, the repair rate coefficient of cotton was substantial, perhaps due to energy storage during

426 high-light illumination of cotton leaf discs, and was lincomycin-sensitive. At the highest irradiance, the difference in the repair rate coefficient, between two orientations in which leaf discs were floated on 428 water, was an order of magnitude, probably reflecting whether oxidative stress exceeded the capacity for detoxifying ROS or not.

430

\section{Acknowledgements}

The support of this work by an Australian Research Council Grant (DP1093827) awarded to W.S.C., the Joint Funds of the National Natural Science Foundation of China grant (No. U1203283) and a

National Key Technology R and D Program of China grant (2007BAD44B07) to Z.W.F., and a Knowledge Innovation Program of the Chinese Academy of Sciences grant (KZCX2-XB3-09-02) to D.-Y. 436 F. is gratefully acknowledged. W.S.C. values the friendship with Gov that started at a meeting in China in 1984. W.S.C. has long admired the work of Pierre J., as well as the life and work of Pierre's grandparents.

\section{References}

Aro E-M, Kettunen R, Tyysjärvi E (1992) ATP and light regulated D1 protein modification and degradation. Role of D1* in photoinhibition. FEBS Lett 297: 29-33

Aro E-M, McCaffery S, Anderson JM (1993) Photoinhibition and D1 protein degradation in peas acclimated to different growth irradiance Plant Physiol 103: 835-843

Aro E-M, Virgin I, Andersson B (1993) Photoinhibition of photosystem II. Inactivation, protein damage 
and turnover. Biochim Biophys Acta 1143: 113-134

Bachmann KM, Ebbert V, Adams III WW, Verhoven AS, Logan BA, Demmig-Adams B (2004) Effects of lincomycin on PSII efficiency, non-photochemical quenching, D1 protein and xanthophylls cycle during photoinhibition and recovery. Func Plant Biol 31: 803-813

450 Chow WS (2001) The photoinactivation of photosystem II in leaves: a personal perspective. J. Photosci 8: 43-53

452 Chow WS, Aro E-M (2005) Photoinactivation and mechanisms of recovery. In: Wydrzynski T and Satoh K (eds) Photosystem II: the light-driven water: plastoquinone oxidoreductase. Advances in photosynthesis and respiration, vol 22 Springer, Dordrecht, pp. 627-648

Chow WS, Hope AB (2004) Electron fluxes through Photosystem I in cucumber leaf discs probed by far-red light. Photosynth Res 81: 77-89

Chow WS, Hope AB, Anderson JM (1989) Oxygen per flash from leaf disks quantifies photosystem II. Biochim. Biophys. Acta 973: 105-108

Chow WS, Fan D-Y, Oguchi R, Jia H, Losciale P, Park Y-I, He J, Öquist G, Shen Y-G, Anderson JM (2012) Quantifying and monitoring functional Photosystem II and the stoichiometry of the two photosystems in leaf segments: Approaches and approximations. Photosynth Res 113: 63-74

462 Ewart AJ (1896) On assimilatory inhibition in plants. J Linn Soc 31: 364-461

Fish LE, Jagendorf AT (1982) High rates of protein synthesis by isolated chloroplasts. Plant Physiol 70: $1107-1114$

Greer DH, Berry JA, Björkman O (1986) Photoinhibition of photosynthesis in intact bean leaves: Role of 466 light and temperature, and requirement for chloroplast-protein synthesis during recovery. Planta 168: 253-260

468 Grossman A, Bartlett S, Chua N-H (1980) Energy-dependent uptake of cytoplasmically synthesized polypeptide by chloroplasts. Nature 285: 625-628 
Plant 118: 297-304

472 Hong S-S, Xu D-Q (1999) Light-induced increase in initial chlorophyll fluorescence $\mathrm{F}_{\mathrm{o}}$ level and the reversible inactivation of PS II reaction centers in soybean leaves. Photosynth Res 61: 269-280

474 Hu Y-Y, Oguchi R, Yamori W, von Caemmerer S, Chow WS, Zhang W-F (2013) Cotton bracts are adapted to a micro-environment of concentrated $\mathrm{CO}_{2}$ produced by rapid fruit respiration. Ann Bot, in press

Kato MC, Hikosaka K, Hirotsu N, Makino A, Hirose T (2003) The excess light energy that is neither utilized in photosynthesis nor dissipated by photoprotective mechanisms determines the rate of photoinactivation in Photosystem II. Plant Cell Physiol 44: 318-325

Klughammer C, Schreiber U (2007) Saturation Pulse method for assessment of energy conversion in PS I.

\section{http://www.walz.com/e_journal/pdfs/PAN07002.pdf}

482 Kou J, Oguchi R, Fan D-Y, Chow WS (2012) The time course of photoinactivation of photosystem II in leaves revisited. Photosynth Res 113: 157-164

484 Kyle DJ, Ohad I, Arntzen CJ (1984) Membrane protein damage and repair: Selective loss of a quinone-protein function in chloroplast membranes. Proc. Acad. Sci. USA 81: 4070-4074

486 Lee H-Y, Hong Y-N, Chow WS (2001) Photoinactivation of photosystem II complexes and photoprotection by non-functional neighbours in Capsicum annuum L. leaves. Planta 212: 332-342

488 Losciale P, Oguchi R, Hendrickson L, Hope AB, Corelli-Grappadelli L, Chow WS (2008) A rapid, whole-tissue determination of the functional fraction of Photosystem II after photoinhibition of leaves based on flash-induced P700 redox kinetics. Physiol Plant 132: 23-32

Losciale P, Chow WS, Corelli Grappadelli L (2010) Modulating the light environment with the peach 'asymmetric orchard': effects on gas exchange performance, photoprotection, and photoinhibition. J 
Exp Bot 61: 1177-1192

494 Mattoo AK, Hoffman-Falk H, Marder JB. and Edelman M (1984) Regulation of protein metabolism: Coupling of photosynthetic electron transport to in vivo degradation of the rapidly metabolized 32-kilodalton protein of the chloroplast membranes. Proc. Natl. Acad. Sci. USA 81: 1380-1384

Melis A (1999) Photosystem-II damage and repair cycle in chloroplasts: what modulates the rate of photodamage in vivo? Trends Plant Sci 4: 130-135.

Miyake C, Miyata M, Shinzaki Y, Tomizawa K-I (2005) $\mathrm{CO}_{2}$ response of cyclic electron flow around PSI (CEF-PSI) in tobacco leaves relative electron fluxes through PSI and PSII determine the magnitude of non-photochemical quenching of Chl fluorescence. Plant Cell Physiol 46: 629-637

Miyata K, Noguchi K, Terashima I (2012) Cost and benefit of the repair of photodamaged photosystem II in spinach leaves: roles of acclimation to growth light. Photosynth Res 113: 165-180

504 Nishimyama Y, Yamamoto H, Allakhverdiev SI, Inaba M, Yokota A, Murata N (2001) Oxidative stress inhibits the repair of photodamage to the photosynthetic machinery. EMBO J 20: 5587-5594

506 Nishimyama Y, Allakhverdiev SI, Murata N (2011) Protein synthesis is the primary target of reactive oxygen species in the photoinhibition of photosystem II. Physiol Plant 142: 35-46

508 Oguchi R, Terashima I, Chow WS (2009) The involvement of dual mechanisms of photoinactivation of photosystem II in Capsicum annuum L. plants. Plant Cell Physiol 50: 1815-1825

510 Oguchi R, Terashima I, Kou J, Chow WS (2011a) Operation of dual mechanisms that both lead to photoinactivation of Photosystem II in leaves by visible light. Physiol Plant 142: 47-55

512 Oguchi R, Douwstra P, Fujita T, Chow WS, Terashima I (2011b) Intra-leaf gradients of photoinhibition induced by different color lights: Implications for the dual mechanisms of photoinhibition and for the application of conventional chlorophyll fluorometers. New Phytologist 191: 146-159.

Ohad I, Kyle DJ, Arntzen CJ (1984) Membrane protein damage and repair: removal and replacement of inactivated 32-kDa polypeptides in chloroplast membranes. J Cell Biol 99: 481-485. 
Ohad I, Kyle DJ, Hirschberg J (1985) Light-dependent degradation of the $\mathrm{Q}_{\mathrm{B}}$-protein in isolated pea thylakoids. EMBO J 4: 1655-1659

Ohad I, Berg A, Berkowicz SM, Kaplan A, Keren N (2011) Photoinactivation of photosystem II: is there more than one way to skin a cat? Physiol Plant 142: 79-86

Powles SB (1984) Photoinhibition of photosynthesis induced by visible light. Annu Rev Plant Physiol 35: $15-44$.

Prásil O, Adir N, Ohad I (1992) Dynamics of photosystem II: mechanism of photoinhibition and recovery processes. In: Barber $\mathbf{J}$ (ed) Topics in Photosynthesis, Vol. 11, Elsevier, Amsterdam, pp. 295-348

Raven JA (2011) The cost of photoinhibition. Physiol Plant 142: 87-104

Samuelsson G, Lönneborg A, Rosenquist E, Gustafsson P, Öquist G (1985) Photoinhibition and reactivation of photosynthesis in the cyanobacterium Anacystis nidulans. Plant Physiol 79: 992-995

Sundby C, McCaffery S, Anderson JM (1993) Turnover of the photosystem II D1 protein in higher plants under photoinhibitory and nonphotoinhibitory irradiance. J Biol Chem 268: 25476-25482

Taniguchi M, Kuroda H, Satoh K (1993) ATP-dependent protein synthesis in isolated pea chloroplasts. FEBS Lett 317: 57-61

Terashima I, Fujita T, Inoue T, Chow WS, Oguchi R (2009) Green light drives leaf photosynthesis more efficiently than red light in strong white light: Revisiting the enigmatic question of why leaves are green. Plant Cell Physiol. 50: 684-697

536 Tyystjärvi E, Aro E-M (1996) The rate constant of photoinhibition, measured in lincomycin-treated leaves, is directly proportional to light intensity. Proc Natl Acad Sci USA 93: 2213-2218

538 Tyystjärvi E (2008) Photoinhibition of Photosystem II and photodamage of the oxygen evolving manganese cluster. Coord Chem Rev 252: 361-376 

and consequences of its oxidizing power. Photosynth Res 38: 297-301

542 Vass I (2011) Role of charge recombination processes in photodamage and photoprotection of the photosystem II complex. Physiol Plant 142: 6-16

544 Wettern M (1986) Localization of 32000 dalton chloroplast protein pools in thylakoids: significance in atrazine binding. Plant Sci 43: 173-177

\section{Figure Legends}

548 Fig. 1. (A) The P700 kinetics area (shaded) used to assay functional PS II. A cotton leaf disc was continuously illuminated by weak far-red light, resulting in the photo-oxidation of almost $90 \%$ of the total photo-oxidizable P700. A single-turnover, saturating flash superimposed on the background far-red light photo-oxidized the remainder of the P700, giving the spike (set to 1.0). Subsequent to the flash, electrons arrived from PS II to $\mathrm{P} 700^{+}$, but the background far-red light brought the $\left[\mathrm{P} 700^{+}\right]$ back to the steady-state level. The trace is an average of four scans. (B) The P700 kinetics area 554 plotted as a function of relative flash intensity $(I)$ as varied by neutral density filters. Leaf discs were either control, non-photoinactivated samples or leaf discs that had been photoinactivated (PI) for $6 \mathrm{~h}$, in the presence or absence of lincomycin. Each data set was fitted by an equation of the form $y=$ $M_{\text {fitted }}\left(1-\mathrm{e}^{-k I}\right)$, yielding both $M_{\text {fitted }}$ and $k$ after a number of iterations, where the $M_{\text {fitted }}$ values are indicated by the horizontal dashed lines. The experimental maximum, $M_{\text {exp }}$, at $100 \%$ of flash intensity was close to the $M_{\text {fitted }}$ value in each case. Each point is a mean of 4 replicates \pm se. (C) The P700 kinetics area, measured at maximum flash energy, as a function of dark time after cessation of actinic illumination $\left(1500 \mu \mathrm{mol} \mathrm{m} \mathrm{s}^{-2}\right.$ for $\left.5 \mathrm{~min}\right)$. The control samples (squares) were exposed to actinic light to steady state. The photoinhibited samples (triangles) were obtained by pre-illumination with white light at $1700 \mu \mathrm{mol} \mathrm{m} \mathrm{s}^{-2}$ for $30 \mathrm{~min}$ in the presence of lincomycin; 
immediately after, they were given actinic illumination $\left(1500 \mu \mathrm{mol} \mathrm{m} \mathrm{m}^{-2} \mathrm{~s}^{-1}\right)$ for $1 \mathrm{~min}$ to maintain steady state prior to measurement. The P700 signals were normalized to the maximum photo-oxidizable P700 obtained after a dark time of $60 \mathrm{~s}$. Each point is a mean of 4 replicates \pm se. The P700 kinetics areas for samples without actinic illumination are indicated by the horizontal dashed lines.

Fig. 2. The P700 kinetics area is linearly correlated with the $\mathrm{O}_{2}$ yield per repetitive, single-turnover saturating flash. Functional PS II content was varied by progressive photoinactivation of PS II in leaf discs in the presence of lincomycin. Measurements were made after the samples had been dark-treated for about 30 min following removal from the high light.

Fig. 3. Recovery of the P700 kinetics area in darkness following photoinactivation treatment at 1800 $\mu \mathrm{mol} \mathrm{m} \mathrm{m}^{-2} \mathrm{~s}^{-1}$ for $72 \mathrm{~min}$ at $15{ }^{\circ} \mathrm{C}$, which approximately halved the functional PS II complexes. Recovery took place (1) in the absence of lincomycin (open circles), (2) in leaf discs that took up lincomycin overnight prior to photoinactivation treatment (solid squares), or (3) in leaf discs infiltrated with lincomycin after the photoinactivation treatment (closed circles). Each point is a mean of 4 replicates \pm se.

Fig. 4. Photoinactivation and recovery of PS II while cotton leaf discs were floated with their abaxial side in contact with water and the adaxial side facing air. Illumination was directed at the adaxial side. The irradiance during recovery was varied from zero to $1300 \mu \mathrm{mol} \mathrm{m} \mathrm{s}^{-2}$ ( $\mu \mathrm{E}$ for short).

582 The time course of photoinactivation of PS II in cotton leaf discs in the presence of lincomycin at various irradiances, including darkness. (B) The time course of recovery of PS II from 584 photoinactivation in the absence of lincomycin. The irradiance during recovery was varied from zero to $1300 \mu \mathrm{mol} \mathrm{m} \mathrm{m}^{-2}$. Cotton leaf discs had been given a photoinactivation treatment to render about half of the PS II complexes inactive before recovery was allowed to occur. Each point is a 
mean of 4 replicates \pm se.

588 Fig. 5. Photoinactivation and recovery of PS II while cotton leaf discs were floated with their adaxial side in contact with water and the abaxial side facing air. Illumination was directed at the adaxial side. The irradiance during recovery was varied from zero to $1300 \mu \mathrm{mol} \mathrm{m} \mathrm{m}^{-2} \mathrm{~s}^{-1}$. (A) The time course of photoinactivation of PS II in cotton leaf discs in the presence of lincomycin at various irrdiances, including darkness. (B) The time course of recovery of PS II from photoinactivation in the absence of lincomycin. Cotton leaf discs had been given a photoinactivation treatment to render $594 \quad$ about half of the PS II complexes inactive before recovery was allowed to occur.

Fig. 6. Rate coefficients of photoinactivation (A) and repair (B) as a function of irradiance. Open circles represent cotton leaf discs floated with the adaxial side facing air while the abaxial side was in contact with a $1 \mathrm{mM}$ lincomycin solution in the determination of $k_{i}$ in (A) or with water in the determination of $k_{r}$ in (B) during recovery. Closed circles represent cotton leaf discs floated with the abaxial side facing air while the adaxial side was in contact with a $1 \mathrm{mM}$ lincomycin solution in the determination of $k_{i}$ or with water in the determination of $k_{r}$ in (B) during recovery. The $k_{i}$ and $k_{r}$ values were derived from the curve fitting in Figs. 4 and 5. Each point is a mean of 4 replicates.

Fig. 7. Response of net carbon assimilation rate $\left(P_{n}\right)$ to irradiance. Each point is a mean of $\mathrm{n}=2$ replicates \pm se.

604 Fig. 8. Total electron transport rate through PS I (ETR1) and the linear electron transport rate through PS II (ETR2) as a function of irradiance. ETR1 and ETR2 were determined using the P700 signal and Chl fluorescence, respectively, for two orientations of cotton leaf discs: (1) the abaxial side faced air while the adaxial side was in contact with water; (2) the adaxial side faced air while the abaxial 
only, by using an RG9 filter to block the actinic light that normally is supplied along with the $810 / 870$

610 nm measuring light by the Dual-PAM, leaving only the actinic light that is supplied along with the Chl fluorescence excitation light. Each point is a mean of 4 replicates \pm se.

612 
Click here to download Line figure: Fig 1.eps
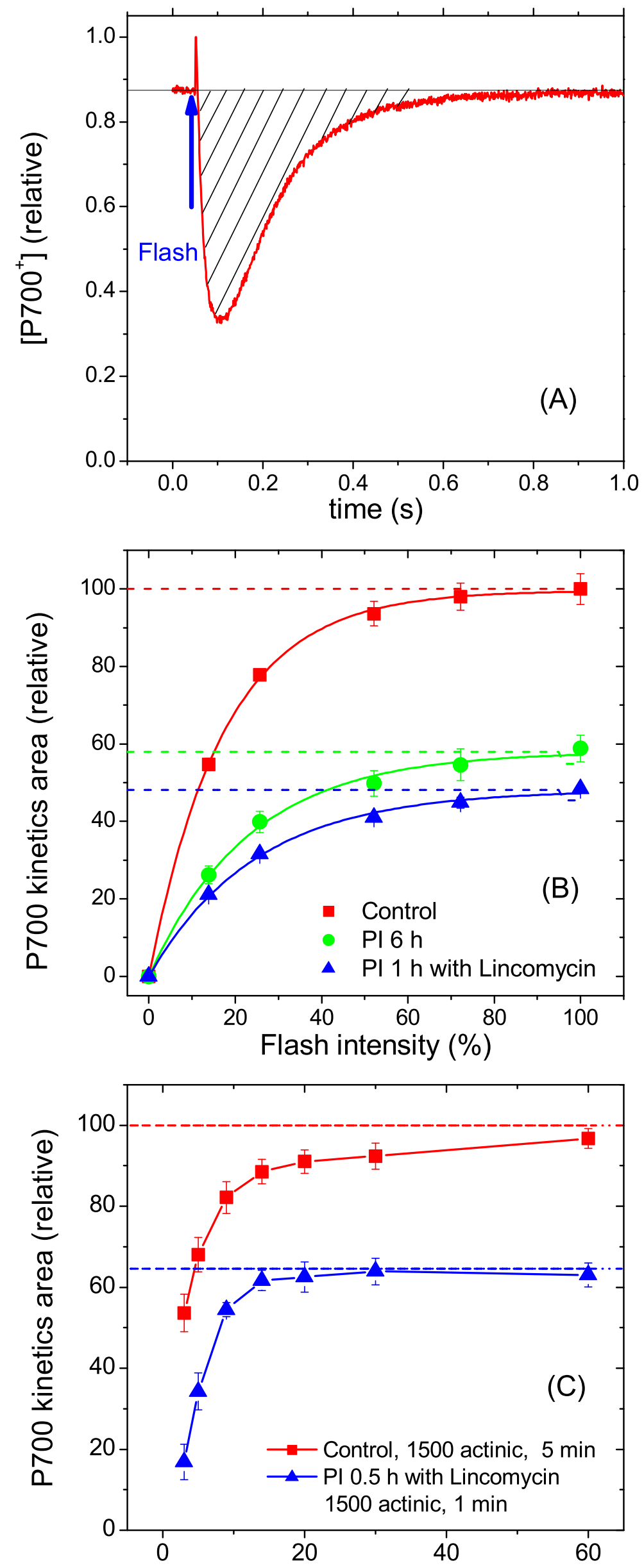

Dark time after actinic illumination (s) 


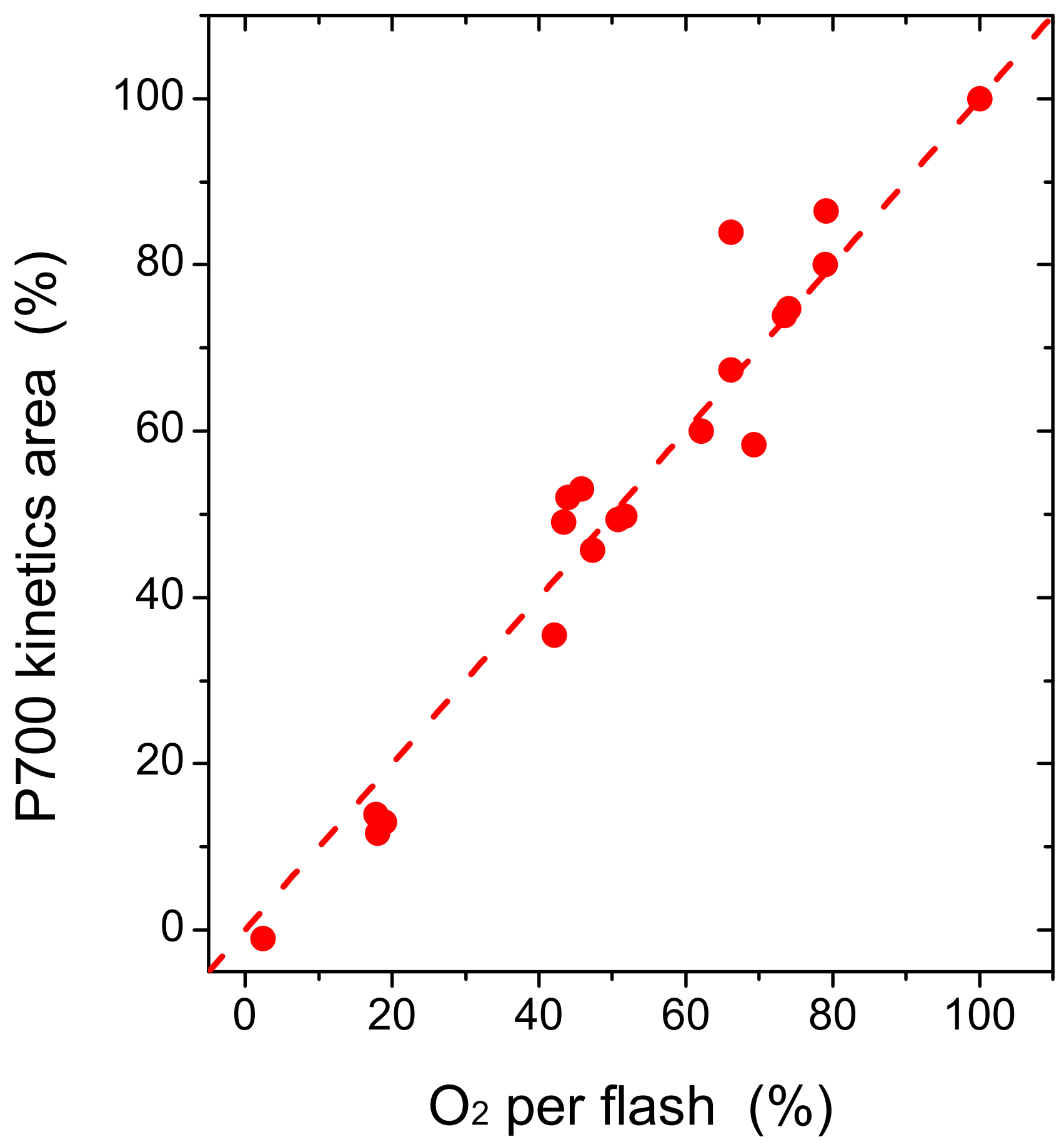




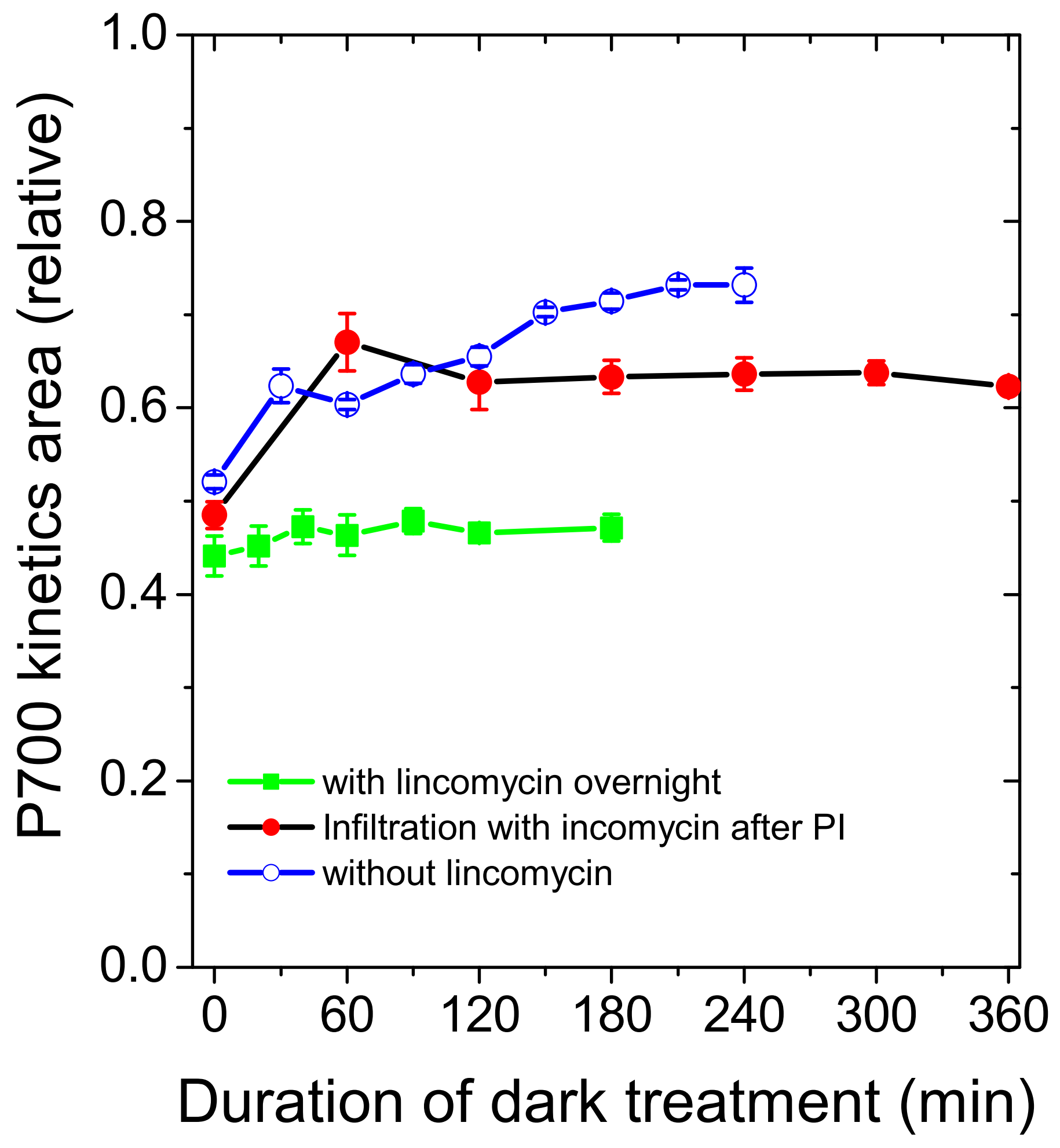



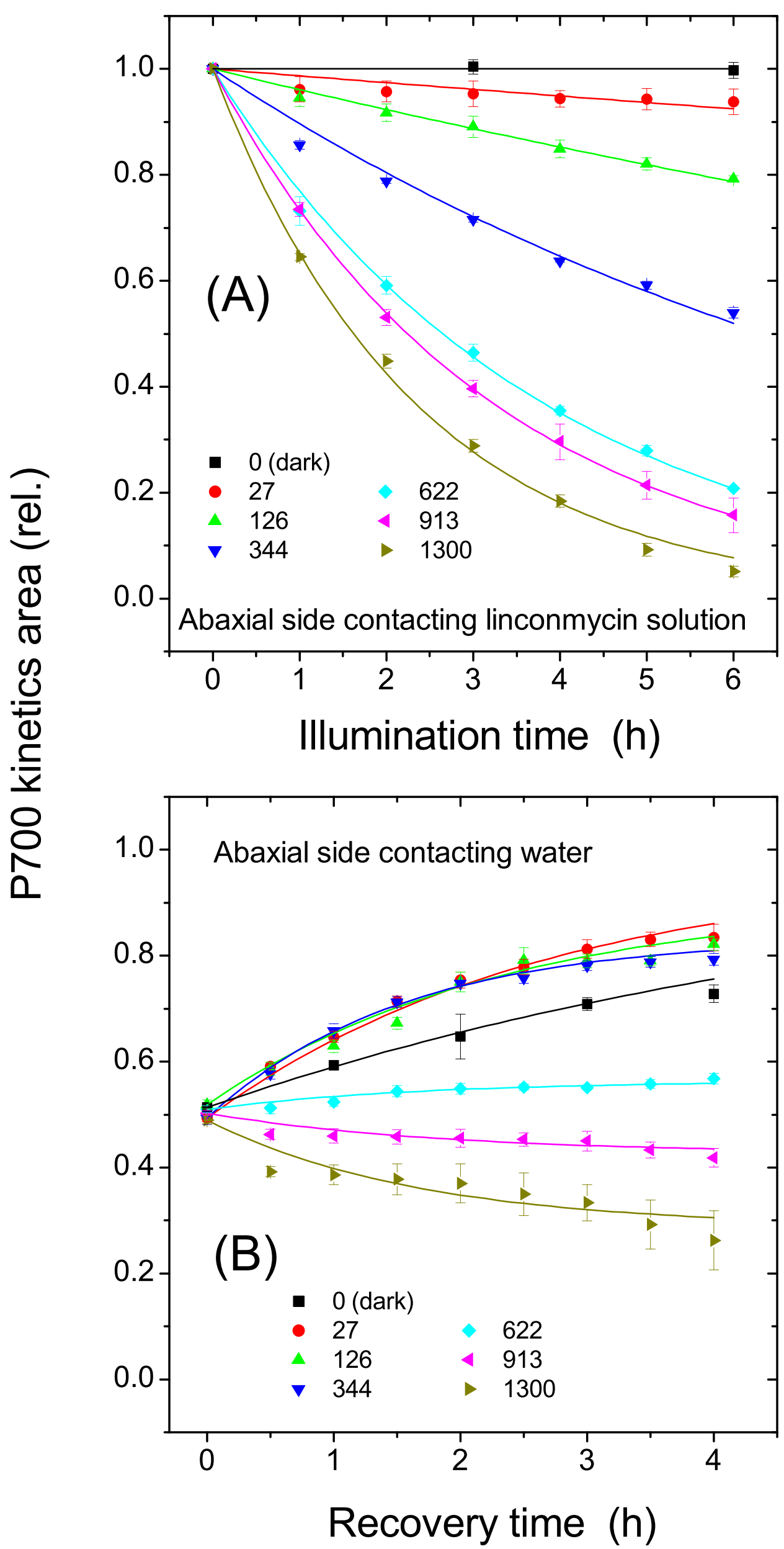


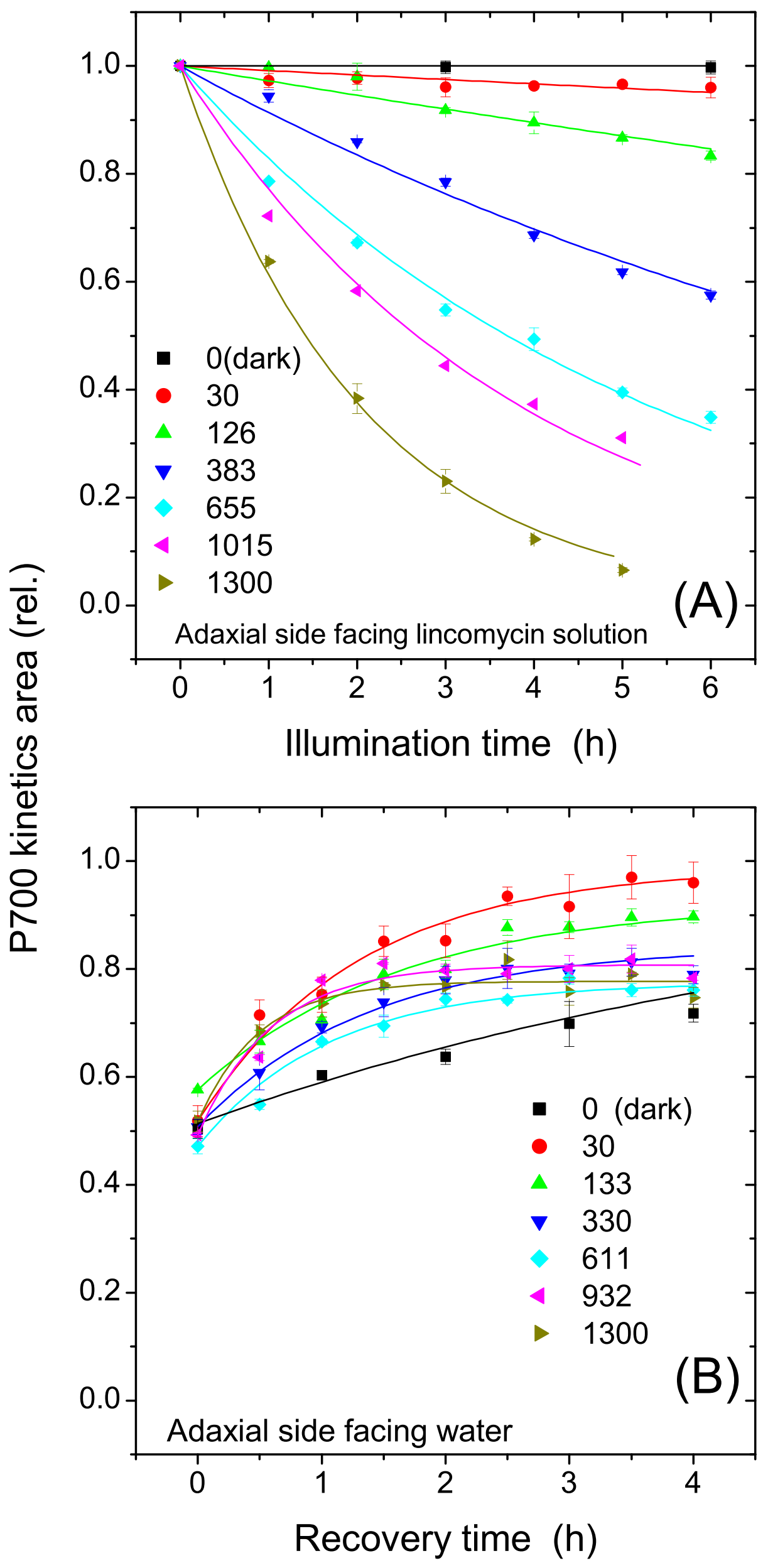



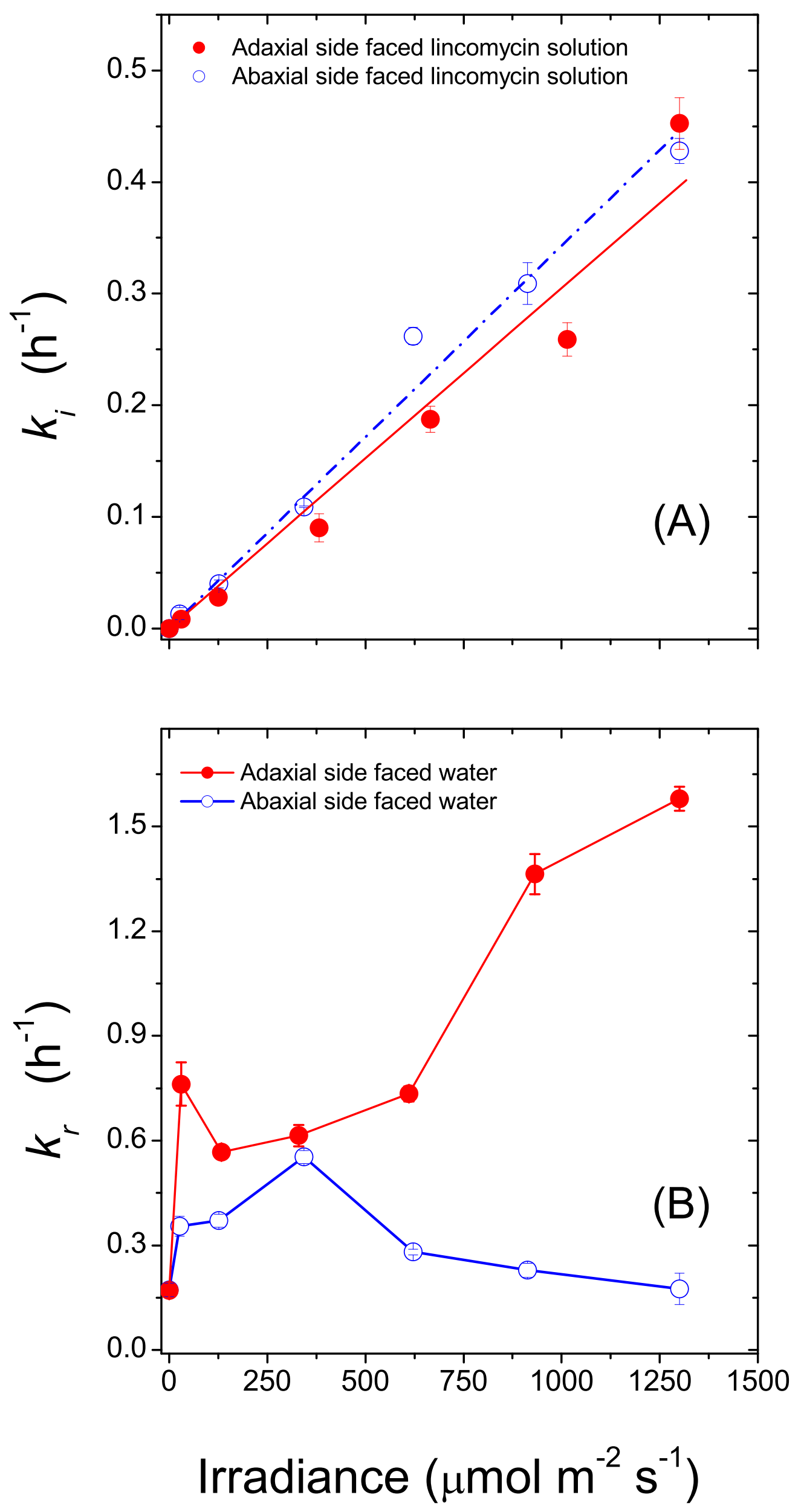


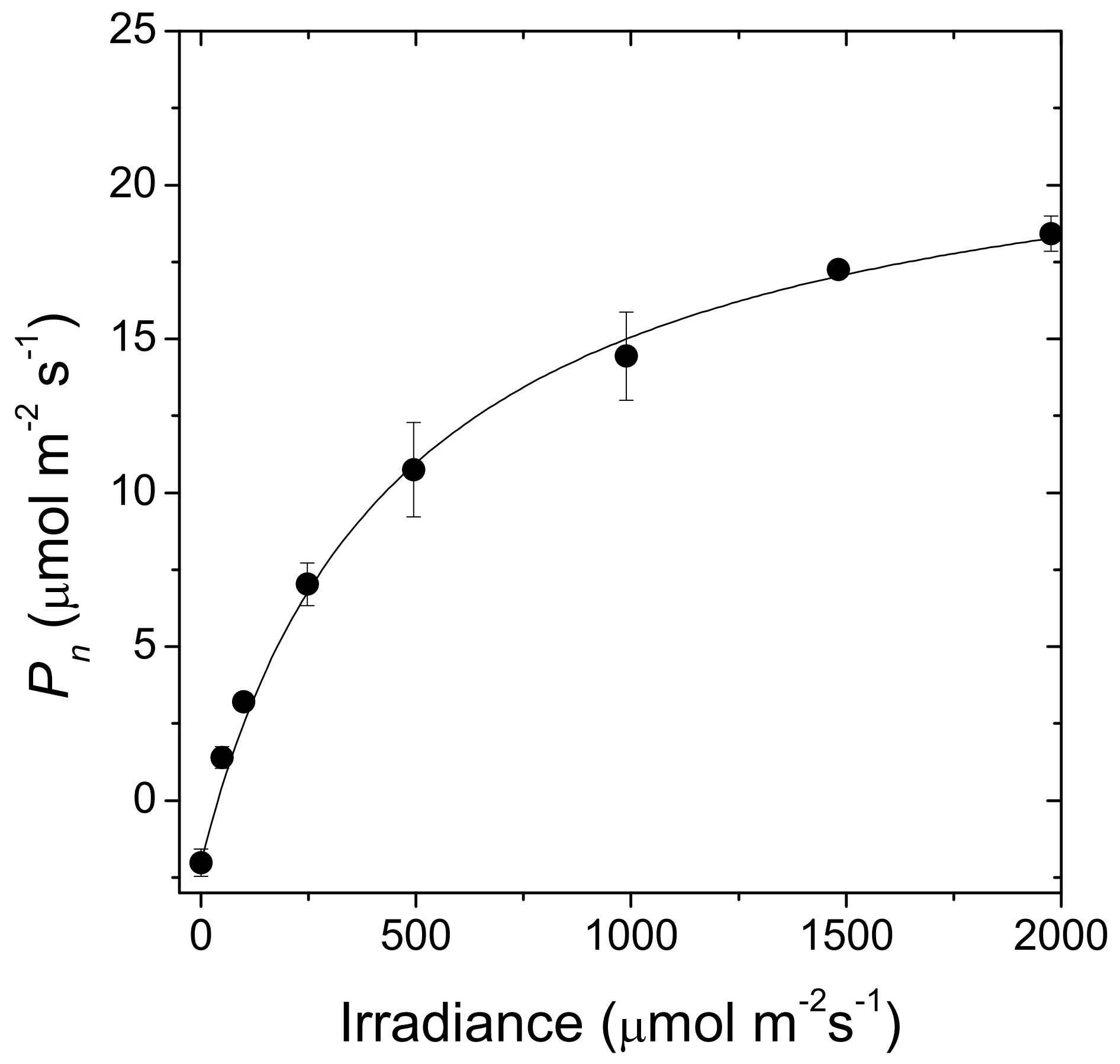




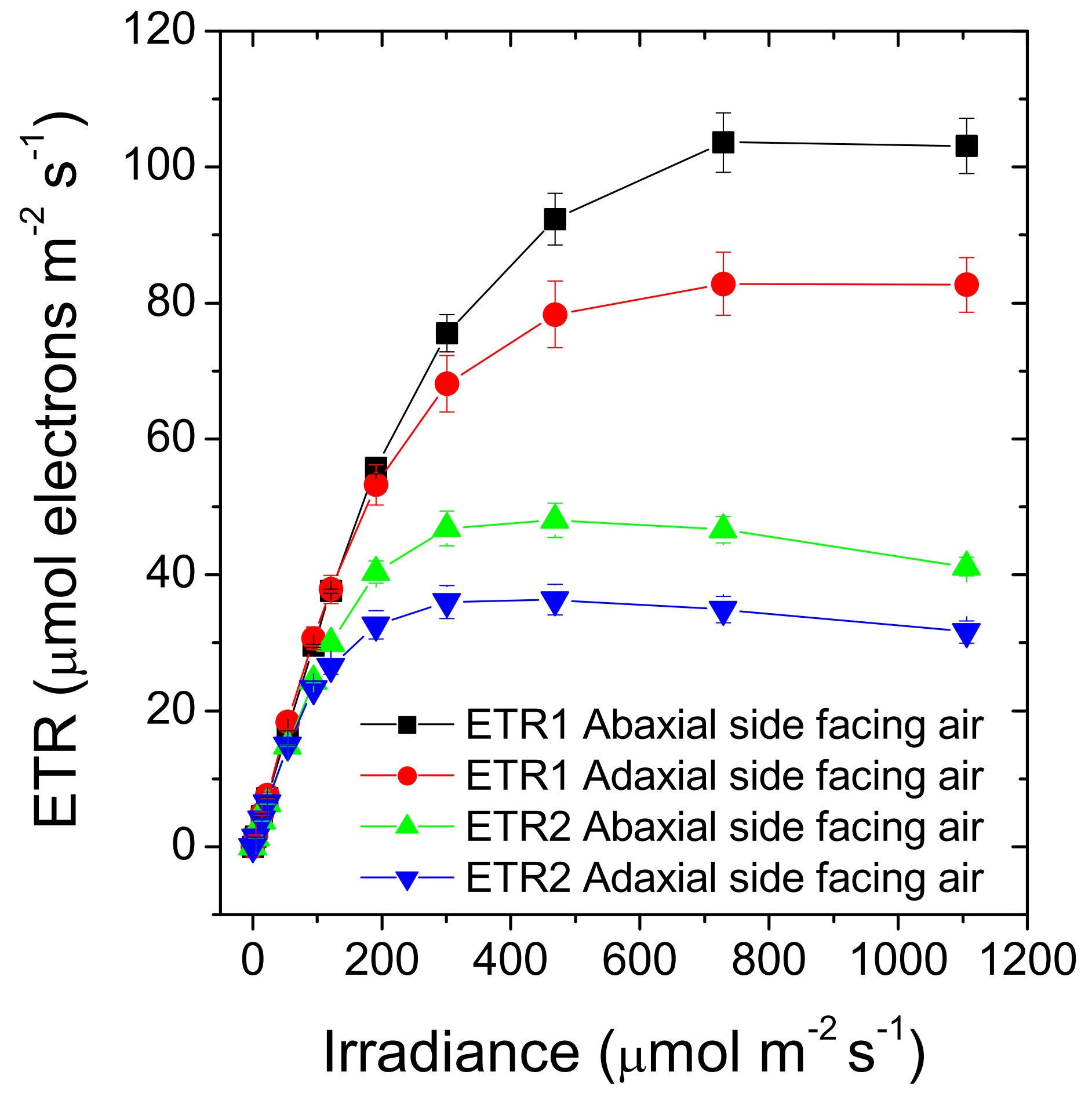

